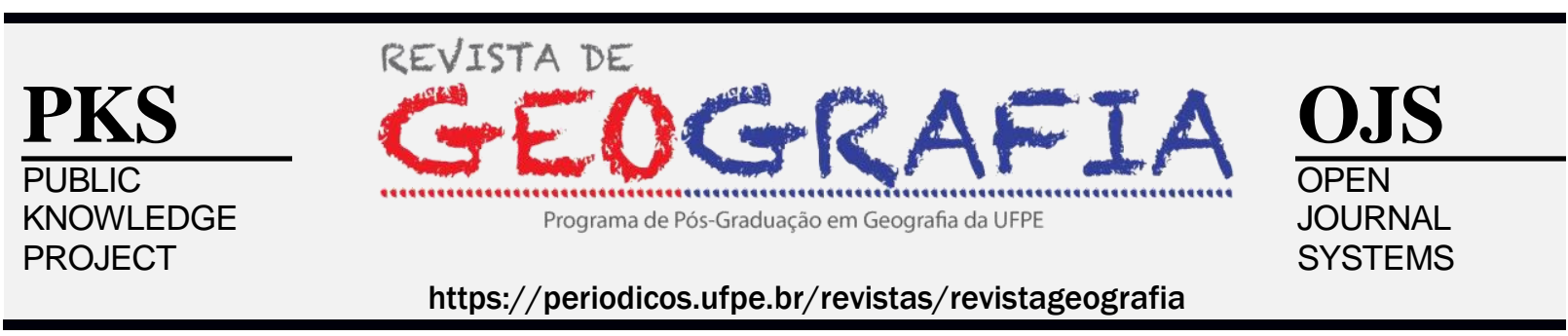

\title{
APLICAÇÃO DA ANÁLISE GEOESPACIAL PARA CARACTERIZAÇÃO DA FRAGILIDADE DE TERRENOS
}

\author{
Dhonatan Diego Pessi ${ }^{1}$, Simoni Maria Loverde-Oliveira ${ }^{2}$
}

${ }^{1}$ Programa de Pós-Graduação em Gestão e Tecnologia Ambiental - UFR. E-mail: dhonatan.pessi@gmail.com
${ }^{2}$ Instituto de Ciências Exatas e Naturais (ICEN) - UFR. E-mail: si.loverde@hotmail.com

Artigo recebido em 10/10/18 e aceito em 12/02/19

\begin{abstract}
RESUMO
O conhecimento sobre a fragilidade dos terrenos constitui um dos principais instrumentos no planejamento territorial considerando a sua utilização no gerenciamento da ocupação do solo. O estudo teve como objetivo realizar o diagnóstico da fragilidade dos terrenos aos processos erosivos na bacia córrego Grande localizada no Assentamento Carimã, Rondonópolis, Mato Grosso, Brasil. A metodologia foi baseada na determinação da suscetibilidade do terreno, onde foram atribuídos pesos aos diferentes fatores. Após o mapeamento por fator foi utilizado a ferramenta raster do QGIS para a sobreposição dos mapas. Na bacia do córrego Grande, 71,5\% da sua área caracterizou-se por baixa a moderada suscetibilidade, onde o tipo de solo, usos da terra e declividade foram fatores importantes e determinantes de baixa fragilidade. As regiões com os menores índices de suscetibilidade estavam com a cobertura vegeta natural preservada. A região central da bacia, local onde há maiores graus de declividade do terreno, solo com menores propriedades de firmeza, amplo cultivo de pastagem e exposição do solo, obtiveram valores de alta suscetibilidade. Os resultados servem como proposta de método prévio às instalações de assentamentos rurais visando conhecer melhor a área, beneficiando a segurança social dos assentados, os recursos naturais e a biodiversidade.
\end{abstract}

Palavras-chave: Fragilidade; Erosão; Cerrado; Assentamento; Usos do solo.

\section{APPLICATION OF GEOSPATIAL ANALYSIS FOR CHARACTERIZATION OF TERRAIN FRAGILITY}

\begin{abstract}
Knowledge about the fragility of the terrain is one of the main instruments in territory planning considering its use in the management of land occupation. The aim of this study was to diagnose fragility of the terrain to erosive processes in the Grande Stream basin located in the Carimã Agricultural Settlement, Rondonópolis, State of Mato Grosso, Central Brazil. The methodology was based on the determination of the susceptibility of the terrain, where weights were assigned to the different factors. After the factor mapping, the QGIS raster tool was used to overlap the maps. In the Grande Stream basin, $71.5 \%$ of the area was characterized by low to moderate susceptibility, where soil type, land use and slope were important factors and determinant of low fragility. The regions with the lowest indices of susceptibility had the natural vegetation cover preserved. The central region of the basin, where there are higher degrees of terrain slope, soil with lower firmness, extensive pasture and soil exposure, achieved high susceptibility values. The results serve as a preliminary methodological proposal for rural settlements to better understand the area, benefiting the social safety of the settlers, natural resources and biodiversity.
\end{abstract}

Keywords: Fragility; Erosion; Cerrado; Settlement; Land use. 


\section{INTRODUÇÃO}

A remoção da cobertura vegetal natural tem causado aumento significativo dos processos erosivos e provocado alterações na dinâmica hidrológica e geomorfológica dos sistemas ambientais (SPORL; ROSS, 2004). Quando o equilíbrio do sistema é quebrado, o sistema pode entrar em colapso, passando para uma situação de risco. A desestabilização do sistema pode ter como indutores tanto processos naturais quanto antrópicos (SPORL; ROSS, 2004). Por esta razão, torna-se cada vez mais importante que exista um planejamento físicoterritorial que considere potencialidades, limitações e a vulnerabilidade destas áreas frente às intervenções antrópicas ainda persistentes (GARÓFALO, 2015).

Avaliar de maneira sistêmica um ambiente constitui a base para o estudo integrado da relação entre os seus elementos naturais, possibilitando um gerenciamento voltado à conservação da paisagem e biodiversidade. A identificação de unidades naturais e dos graus de fragilidade da paisagem proporcionam melhores definições para a etapa de planejamento territorial, base para traçar diretrizes e propor ações de zoneamento e gestão das áreas especiais (VALLE, 2016; SPORL; ROSS, 2004). Estudos e investigações que buscam dar suporte à avaliação do meio físico natural, integrando as atividades antrópicas, são considerados de extrema importância no planejamento e ordenamento territorial, compatibilizando o desenvolvimento socioeconômico com a conservação do meio ambiente (CALIJURI, 2007).

Nesse sentido, é importante que as bases da análise ambiental e o planejamento territorial têm como base as condições da paisagem e as características naturais da região, principalmente informações como declividade, classes pedológicas e geomorfológicas, intensidade pluviométrica, uso da terra e cobertura vegetal, de forma a viabilizar um efetivo gerenciamento ambiental (BOJÓRQUEZ-TAPIA et al., 2013; VALLE, 2016; ROSS, 2012).

O uso de geotecnologia na produção de mapas de fragilidade dos ambientes são ferramentas que atendem a necessidade quanto ao planejamento e gestão dos recursos naturais. São instrumentos de avaliação das fragilidades e potencialidades que sintetizam as características naturais dos meios e as restrições e/ou aptidões em face de distintas formas de uso e ocupação. A elaboração de mapas de fragilidade ambiental mostra, assim, em termos de intensidade e de distribuição espacial, a susceptibilidade do meio físico, considerando-se os fatores geológicos, geomorfológicos e pedológicos, e as suas respostas às pressões antrópicas (SANTOS, 2010; FRANCISCO et al., 2008). 
O mapeamento da fragilidade ambiental constitui um dos principais instrumentos empregados pelos órgãos públicos na elaboração do planejamento territorial ambiental, possibilitando a indicação de áreas onde os graus de fragilidade são menores e mais altos, fornecendo deste modo, importantes subsídios para a gestão territorial (SANTOS, 2010).

O presente trabalho teve como objetivo realizar o diagnóstico da fragilidade ambiental da bacia hidrográfica córrego Grande visando analisar a susceptibilidade natural dos terrenos aos processos erosivos.

\section{MATERIAL E MÉTODOS}

Área de estudo

A bacia córrego Grande está localizada ao sul do município de Rondonópolis (Mato Grosso), possui uma área de $88,58 \mathrm{~km}^{2}$, com 16,80 km de extensão, apresentando largura média de $5,37 \mathrm{~km}$, com perímetro de $58 \mathrm{~km}$ (Figura 1). As nascentes e o curso d'água do córrego Grande até seu ponto exutório estão inseridos no assentamento Carimã. As Áreas de Proteção Permanente do córrego Grande são formadas por vegetação de Cerrado do tipo Mata de Galeria, Veredas e Campos Encharcados (EREIO, 2018).

O assentamento Carimã (Figura 1) está localizado nas coordenadas 16³9’21"S e 5449'17"W, possui uma área com 5.989 hectares divididos em 195 lotes. Parte do assentamento encontra-se dentro da Zona de Amortecimento dos impactos ao Parque Estadual Dom Osório Stoffel. Este Assentamento foi criado no ano de 1997 sob-responsabilidade do Instituto Nacional de Colonização e Reforma Agrária (INCRA) (EREIO, 2018). 
Figura 1 - Localização da bacia hidrográfica córrego Grande e do Assentamento Carimã ao sul do município de Rondonópolis-MT.

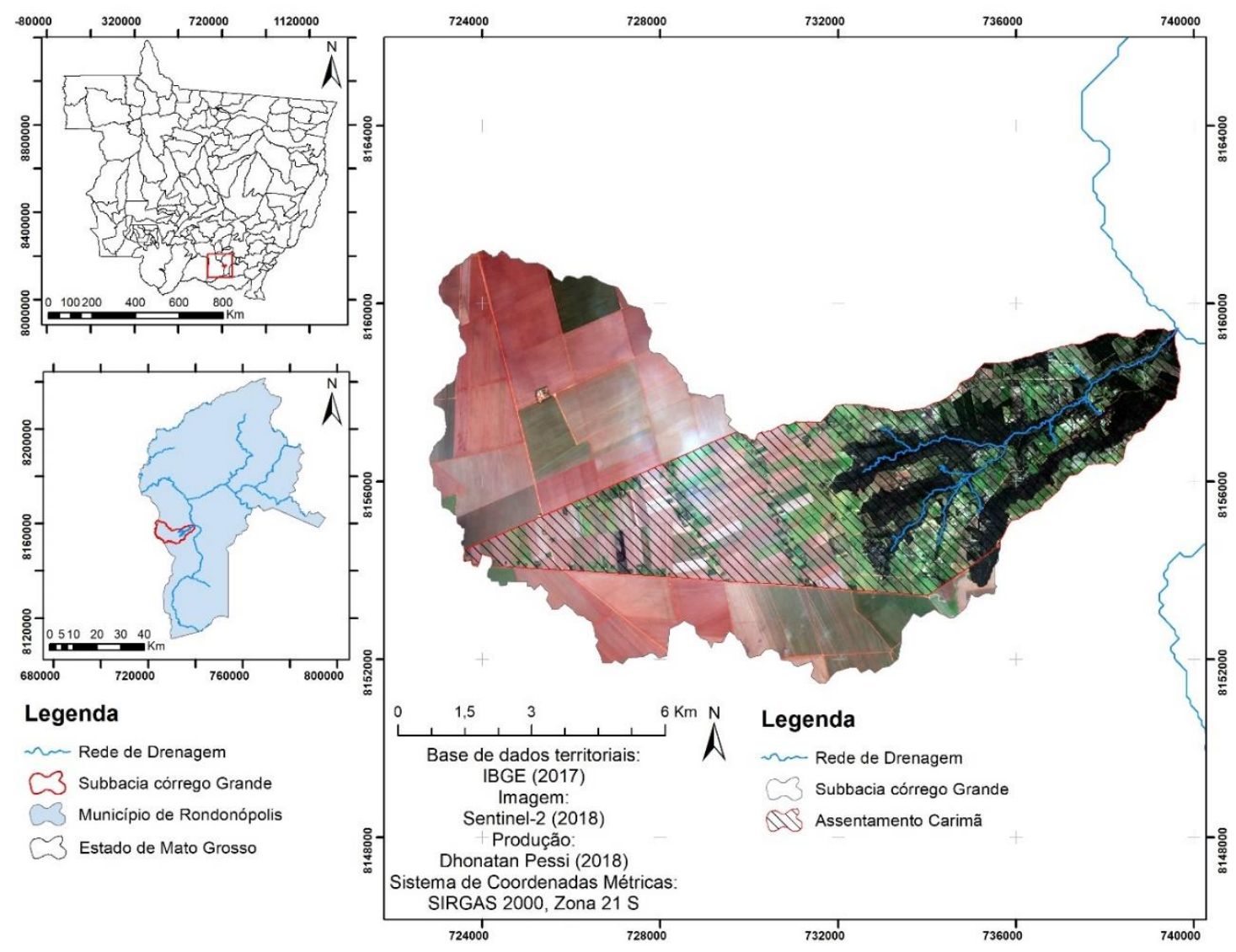

Fonte: Os autores.

A região da bacia possui uma declividade de $528 \mathrm{~m}$ das nascentes até o ponto exutório sendo ele o rio Vermelho, na Região Hidrográfica do Alto Paraguai. O relevo é constituído de terrenos altiplanos, com chapadões levemente ondulados e escarpas abruptas. Os tipos de solos predominantes são Latossolo Vermelho nos altiplanos e o Podzólico Vermelho-Amarelo nas regiões de relevo ondulado (MIRANDA, 2014).

O clima local é considerado tropical, consistindo em uma temperatura média anual de $25^{\circ} \mathrm{C}$, sendo a média das máximas de $32,6^{\circ} \mathrm{C}$ e a média das mínimas $18,6^{\circ} \mathrm{C}$. A precipitação e evapotranspiração anual é de 1416,07mm e 1404,50 mm, respectivamente. As estações seca e chuvosa são bem definidas, em média com totais acumulados variando de 88 a $1321 \mathrm{~mm}$ (SETTE, 2001; SOUZA et al., 2013).

A vegetação regional está composta por Cerradão, Cerrados, Formação Savânica associada a vertentes e Floresta Estacional. Os fragmentos de vegetação presentes na área de estudo são classificados como Mata Ciliar que é considerada semidecídua com composição 
florística típica e com diferentes graus de caducifólia na estação seca. Os portes podem variar de 20 a 25 metros (SEPLAN, 2011).

\section{Procedimento metodológico}

A metodologia desse trabalho foi baseada numa adaptação do trabalho realizado por Suarez (2009) na determinação da suscetibilidade do terreno ao deslizamento. O trabalho foi dividido em três etapas: i) determinar os pesos de nível de fragilidade para as diferentes variáveis ambientais que estão relacionadas à suscetibilidade do terreno, ii) produção dos mapas para cada variável ambiental, iii) sobreposição dos mapas.

Determinação dos pesos atribuídos às variáveis ambientais

A definição dos valores (pesos) para avaliar o nível de suscetibilidade do terreno, seguiu os valores já definidos por Suarez (2009) que vai de uma escala de 0 a 1 conforme apresentado na Tabela 1.

Tabela 1 - Pesos para Avaliar o Nível de Suscetibilidade do Terreno.

\begin{tabular}{ccc}
\hline \multicolumn{3}{c}{ Valor Total de Suscetibilidade } \\
\hline Classe & Valor & Descrição da suscetibilidade \\
\hline 1 & $0.00-0.20$ & Muito Baixa \\
2 & $0.20-0.40$ & Baixa \\
3 & $0.40-0.60$ & Moderada \\
4 & $0.60-0.80$ & Alta \\
5 & $>0.80$ & Muito Alta \\
\hline
\end{tabular}

Fonte: Adaptado de Suarez (2009).

O trabalho de Suarez (2009) segue a hipótese de pesquisa de que a ocorrência de processos erosivos lineares (ravinas) e de movimentos de massa (escorregamentos) depende de seis fatores: uso da terra, declividade do terreno, probabilidade de ocorrência de chuvas intensas, características pedológicas, geomorfológicas e litológicas. Na Tabela 2 são apresentados os fatores e suas principais características, assim como os respectivos pesos atribuídos para cada característica. 
Tabela 2 - Pesos dos Diferentes Fatores para Calcular o Nível de Suscetibilidade do Terreno da Bacia Hidrográfica Córrego Grande.

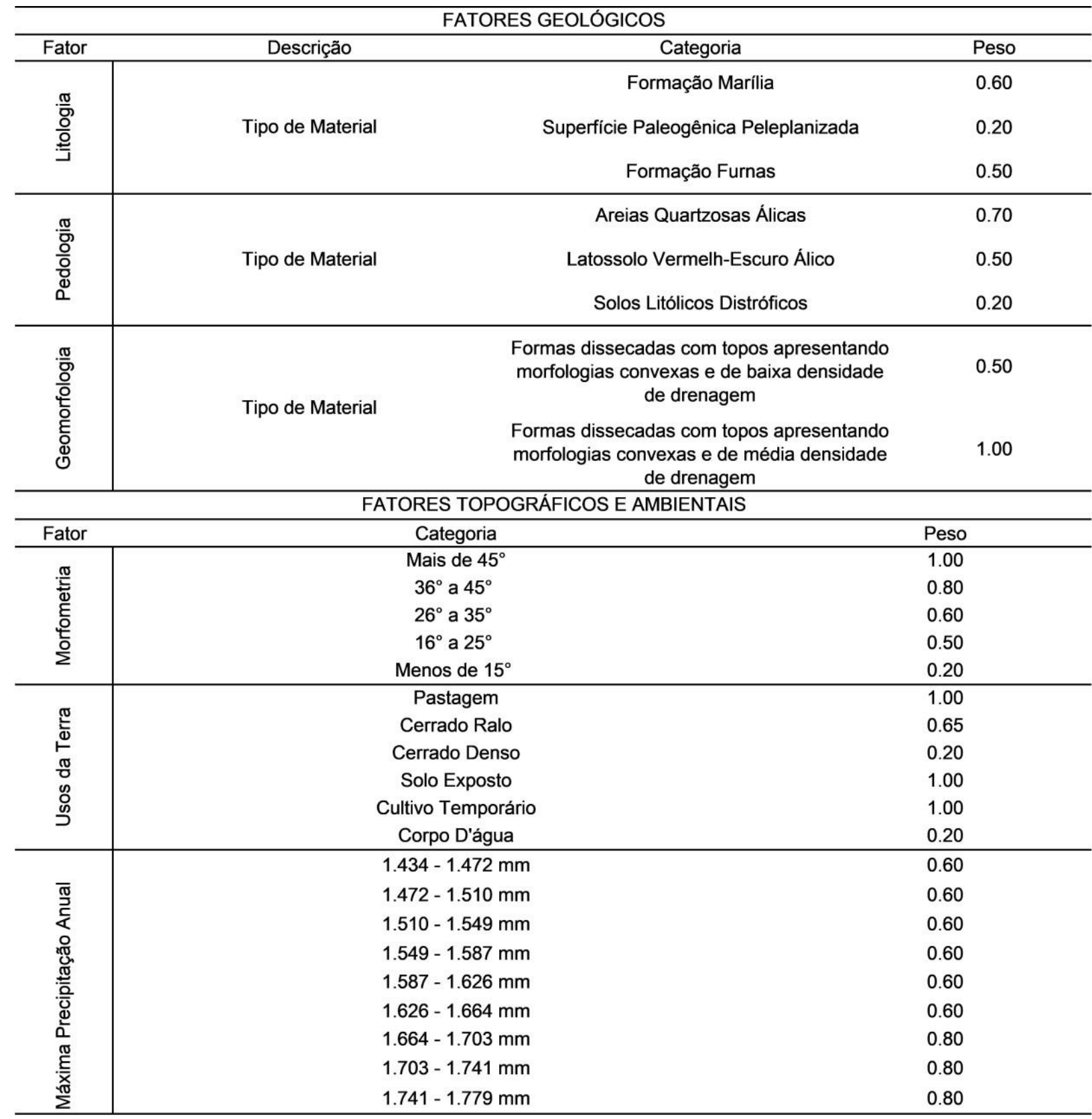

Fonte: Adaptado de Suarez (2009).

Produção de mapas para cada fator

Para a produção dos mapas de pedologia, litologia, pluviometria e geomorfologia, foi consultado o banco de dados da SEPLAN (Secretaria de Estado de Planejamento do Estado do Mato Grosso), (disponível: http://www.seplan.mt.gov.br/-/3952799-dsee-portalinterativo?ciclo $=$ cv_gestao_inf) que disponibiliza dados cartografados. Os dados foram 
exportados para o software QGIS 3.0 e vetorizados para a produção de dados raster e posteriormente para a produção dos mapas.

Os dados de pluviometria considerou a pluviosidade anual média desde 1983 até 1994. Os dados de chuva foram disponibilizados pela SEPLAN em elementos cartográficos com as isoietas já estabelecidas com as médias anuais para todo o Estado do Mato Grosso. Foi realizado apenas a vetorização das informações coletadas.

A confecção do mapa de uso da terra foi através de técnicas de classificação supervisionada realizadas no QGIS. A imagem utilizada para tanto, foi do satélite Sentinel-2 do mês de março de 2018 (disponível: https://earthexplorer.usgs.gov/).

O mapa de declividade do terreno foi produzido através de uma imagem MDT (Modelo Digital de Terreno) disponibilizada pelo INPE (Instituto Nacional de Pesquisas Espaciais) (VALERIANO, 2008). Através de ferramentas disponíveis no QGIS, pôde se obter uma imagem com valores em graus quanto à declividade do terreno da bacia estudada.

\section{Sobreposição de mapas}

Após a produção de todos os mapas referentes a cada fator, foi utilizada a ferramenta calculadora raster do QGIS para a sobreposição dos mapas, assim como também foi aplicada uma álgebra na divisão destes mapas. O esquema da Figura 2 mostra os mapas usados na sobreposição e a álgebra usada na divisão destes mapas.

Esquema demonstrativo da sobreposição dos mapas de cada fator e aplicação da álgebra na ferramenta calculadora raster do QGIS. 
Figura 2 - a) mapa de geomorfologia; b) mapa de pluviometria; c) mapa de pedologia; d) mapa de declividade; e) mapa de litologia; f) mapa de uso da terra.

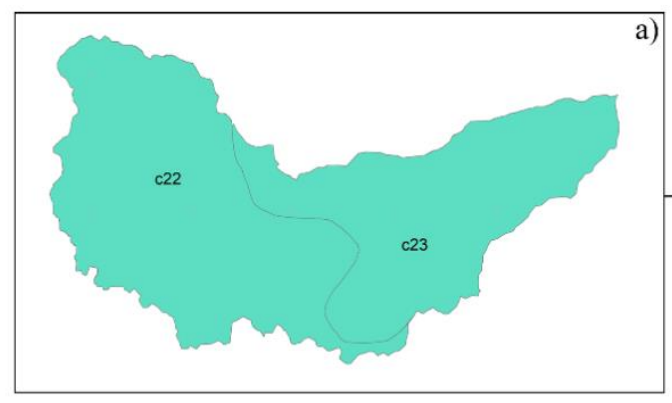

a)
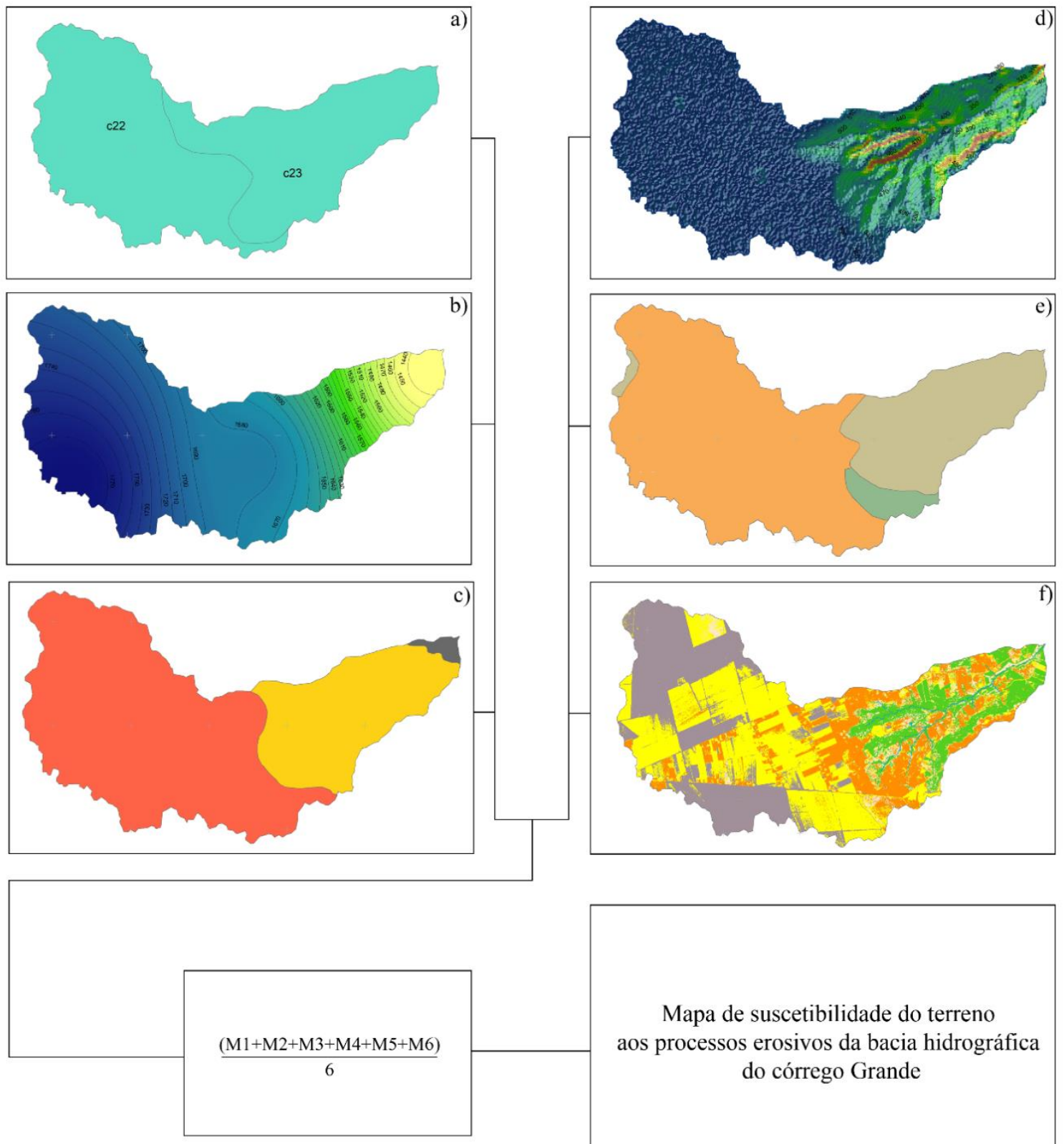

Mapa de suscetibilidade do terreno aos processos erosivos da bacia hidrográfica do córrego Grande

Fonte: Os autores. 


\section{RESULTADOS E DISCUSSÃO}

O cruzamento dos dados de pedologia, geomorfologia, litologia, usos da terra, declividade e pluviometria permitiu a geração do mapa de susceptibilidade do terreno à erosão para a bacia hidrográfica córrego Grande (Figura 3). Para todas as características analisadas na área de estudo foram atribuídos graus de suscetibilidade que vai desde 0,41 (baixa suscetibilidade) a 0,83 (alta suscetibilidade), que agrupados resultaram em três graus de fragilidade dos terrenos (Baixo, Moderado e Alto).

Figura 3 - Mapa com as áreas de maior a menor suscetibilidade do terreno à erosão para a bacia hidrográfica do córrego Grande Rondonópolis-MT.

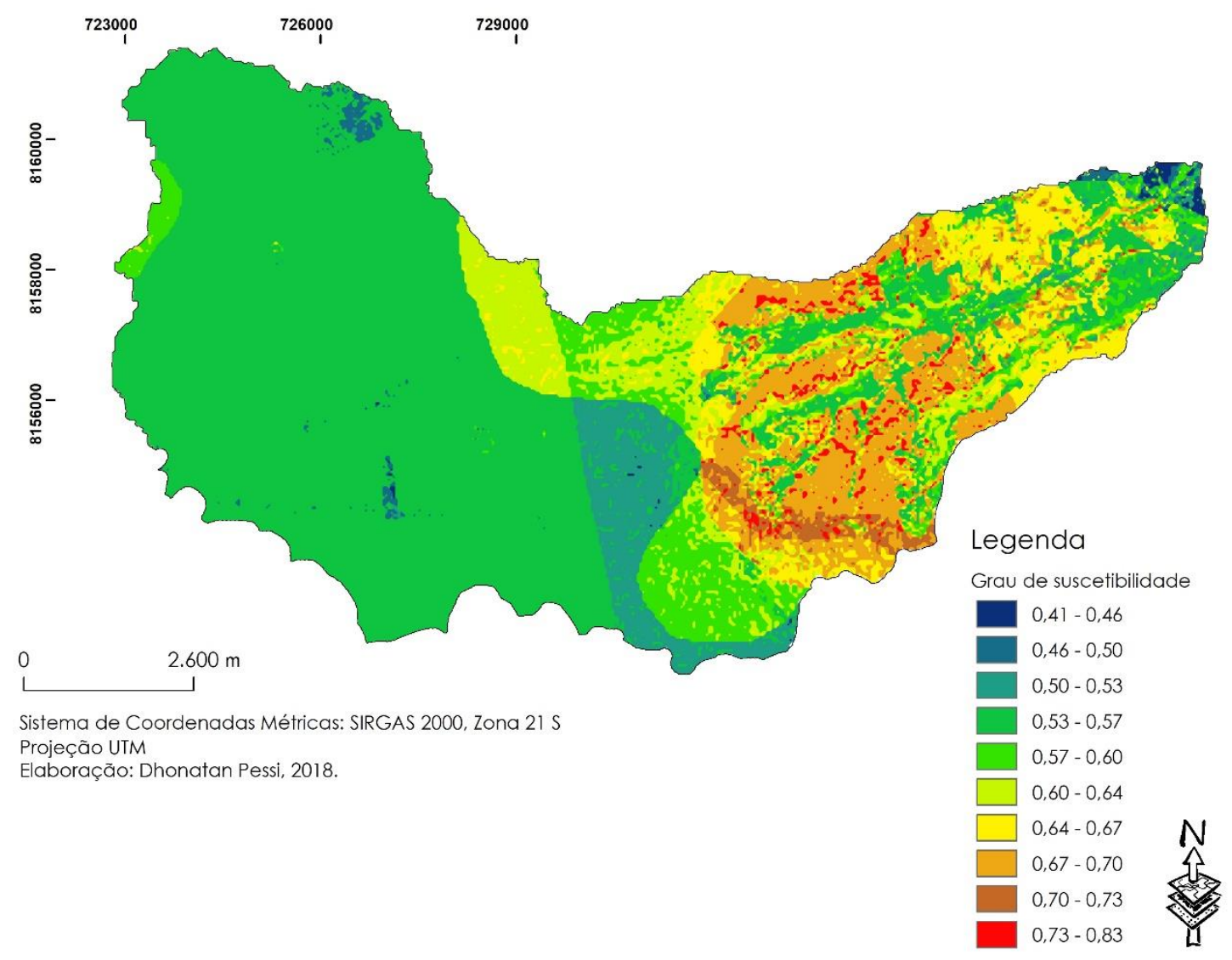

Fonte: Os autores. 
Para todas as características analisadas na área de estudo foram atribuídos graus de suscetibilidade que vai desde 0,41 (baixa suscetibilidade) a 0,83 (alta suscetibilidade), que agrupados resultaram em três graus de fragilidade dos terrenos (Baixo, Moderado e Alto).

A análise do mapa permite concluir que existe predomínio espacial de áreas com baixa e moderada susceptibilidade do terreno aos movimentos de massa caracterizando $71,5 \%$ da área territorial da bacia, e áreas com alta suscetibilidade totalizando 28,5\% da área da bacia. A área total da bacia ficou estimada em 8.690 hectares. Na Figura 4 estão representados os valores de área em hectares para cada um dos graus de fragilidade observados na bacia.

Figura 4 - Representatividade de cada grau de suscetibilidade em hectares para a área da bacia hidrográfica do córrego Grande.

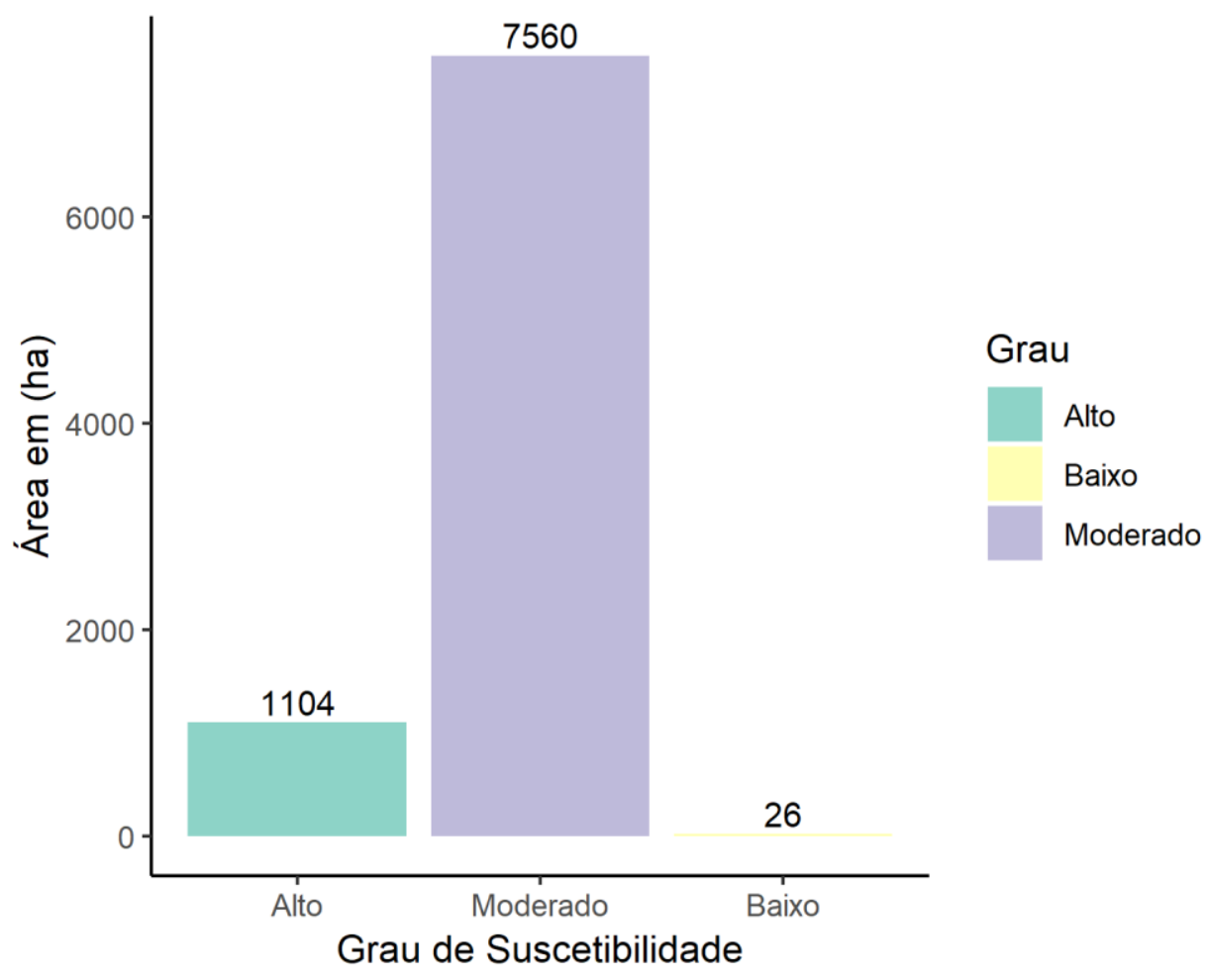

Fonte: Os autores.

Nota-se que o grau moderado foi o mais representativo para toda a área da bacia, correspondendo 7.560 hectares. Na sequência o grau alto com 1.104 hectares e o grau baixo com 26 hectares. O grau moderado está mais representado na região alta da bacia, local onde há pouca vegetação, solo exposto para cultivo de monocultura. Já o grau alto está presente na região central da bacia, região a qual possui maiores declínios do terreno, solo mais frágil e áreas de pastagem para o gado (Figura 3 e Figura 4). 
Conforme Santos (2013) descreve em seu trabalho, o solo, a declividade, os tipos de usos da terra e a intensidade pluviométrica, caracterizam-se como os principais fatores condicionantes dos processos erosivos. Os demais fatores estão relacionados aos processos de erosão de maneira indireta, mas que contribuem para a suscetibilidade do terreno.

O mapa de suscetibilidade do terreno à ocorrência de erosão e escorregamentos (movimentos de massas) (Figura 3) mostra que as áreas da região mais baixa da bacia são mais suscetíveis a este tipo de processo, apresentando baixa densidade de vegetação e declividade mais acentuada, conforme pode ser constatado nos mapas da Figura 5.

Figura 5 - a) mapa de intensidade pluviométrica; b) mapa de declividade do terreno; c) mapa de usos da terra.

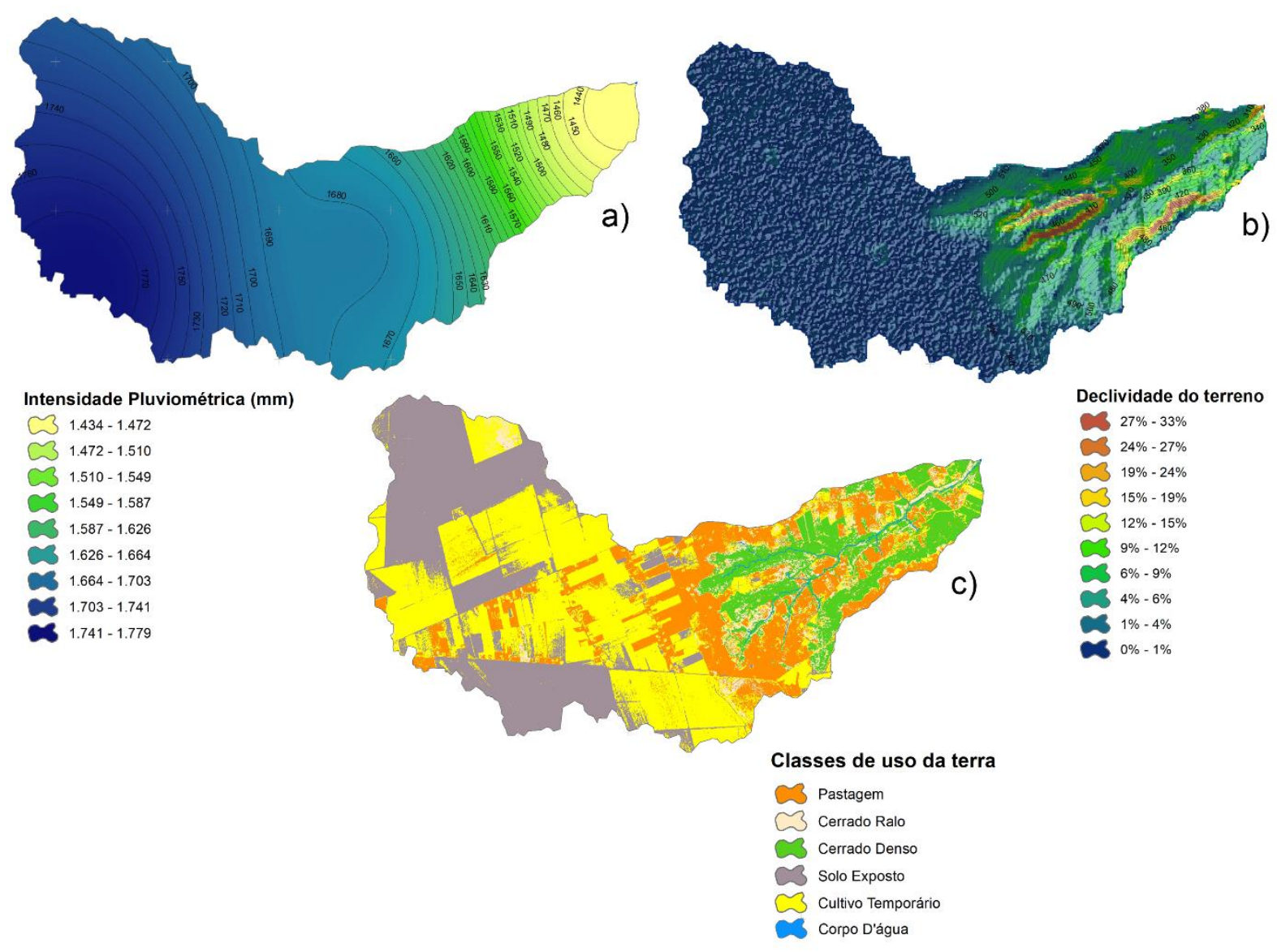

Fontes: Os autores. 
As precipitações para a região da bacia do córrego Grande é marcada por regime tropical de chuvas, regido pelos sistemas regionais de circulação atmosférica, concentrandose, essencialmente, no verão. A distribuição espacial das precipitações é influenciada pela forma e altitude do relevo, que se distribui em faixas altimétricas distintas. A estação chuvosa e úmida de verão se estende, geralmente, de outubro a março ou abril, registrando-se nesse período um considerável excedente hídrico e mantendo elevados índices de umidade no período. As médias anuais dos últimos 10 anos variaram de $1434 \mathrm{~mm}$ a 1779 mm, com maior intensidade nas regiões mais altas da bacia. Na região mediana da bacia, na qual foram registrados os maiores graus de suscetibilidade do terreno, obteve índices pluviométricos de $1650 \mathrm{~mm}$ a $1680 \mathrm{~mm}$, o que caracteriza altos índices de intensidade de chuvas para essa área.

A quantidade de chuva e a intensidade com a qual ela atinge o solo estão diretamente ligadas aos problemas de perda de solo e erosão (BIGARELLA, 2007). Além disto, as vias de circulação aceleram o escoamento pluvial, intensificando os processos erosivos e o transporte de sedimentos (FORMAN; ALEXANDER, 1998).

A falta de cobertura natural e o uso do solo para atividades humanas estão presentes na bacia, sendo que os principais usos presentes são a pastagem, solo exposto e cultivo temporário. Na região central da bacia ocorre a maior presença de pastagem devido a presença dos lotes do Assentamento Carimã. O tipo de uso da terra influencia diretamente na vulnerabilidade do terreno à ação de agentes erosivos e a erodibilidade do solo depende diretamente da capacidade de infiltração da água (SANJAY; GOEL, 2002).

A pastagem sofre processo de degradação com a ação evolutiva da perda de vigor e produtividade forrageira, sem possibilidade de recuperação natural, que afeta a produção e o desempenho animal e culmina com a degradação do solo e dos recursos naturais em função de manejo inadequado (CUNHA, 2013).

Segundo Cunha (2013), a cobertura vegetal de áreas próximas de corpos d'água e com terrenos mais íngremes possui um papel importante na função de estabilização dessas vertentes. Seguindo esse pressuposto, Bertoni (2008) atribui cobertura vegetal como a defesa de um terreno contra a erosão.

A partir do mapa de declividade do terreno, nota-se que o alto grau de suscetibilidade do terreno está associado às áreas de morro que possuem relevo ondulado e forte ondulado. Essas áreas estão localizadas na região central da bacia onde o terreno é menos regular. Normalmente, as áreas mais declivosas apresentam maior susceptibilidade, pois apresentam condições topográficas favoráveis à ocorrência de processos erosivos e movimentos de massa. 
A parte central da bacia possui os maiores percentuais de inclinação do terreno por se tratar de uma região onde o corpo hídrico principal corre. Nessas regiões os valores associados ao declive do terreno variam de $19^{\circ}$ a $33^{\circ}$. Segundo Cogo et al. (2003), o aumento da declividade é um dos fatores que influência fortemente nos processos de erosão, sobretudo na erosão hídrica do solo, pois, à medida que ela aumenta, aumentam o volume e a velocidade da enxurrada e diminui a infiltração de água no solo.

Além disso, a região central e parte da jusante da bacia possuem características próprias e diferentes da região mais alta da bacia quanto ao tipo de solo e rochas, acentuando ainda mais a suscetibilidade nessa região. Na Figura 6 estão representados os respectivos mapas de classe do solo, de rochas e geomorfologia.

Figura 6 - a) mapa das classes de rocha; b) mapa das classes de solo; c) mapa de geomorfologia.

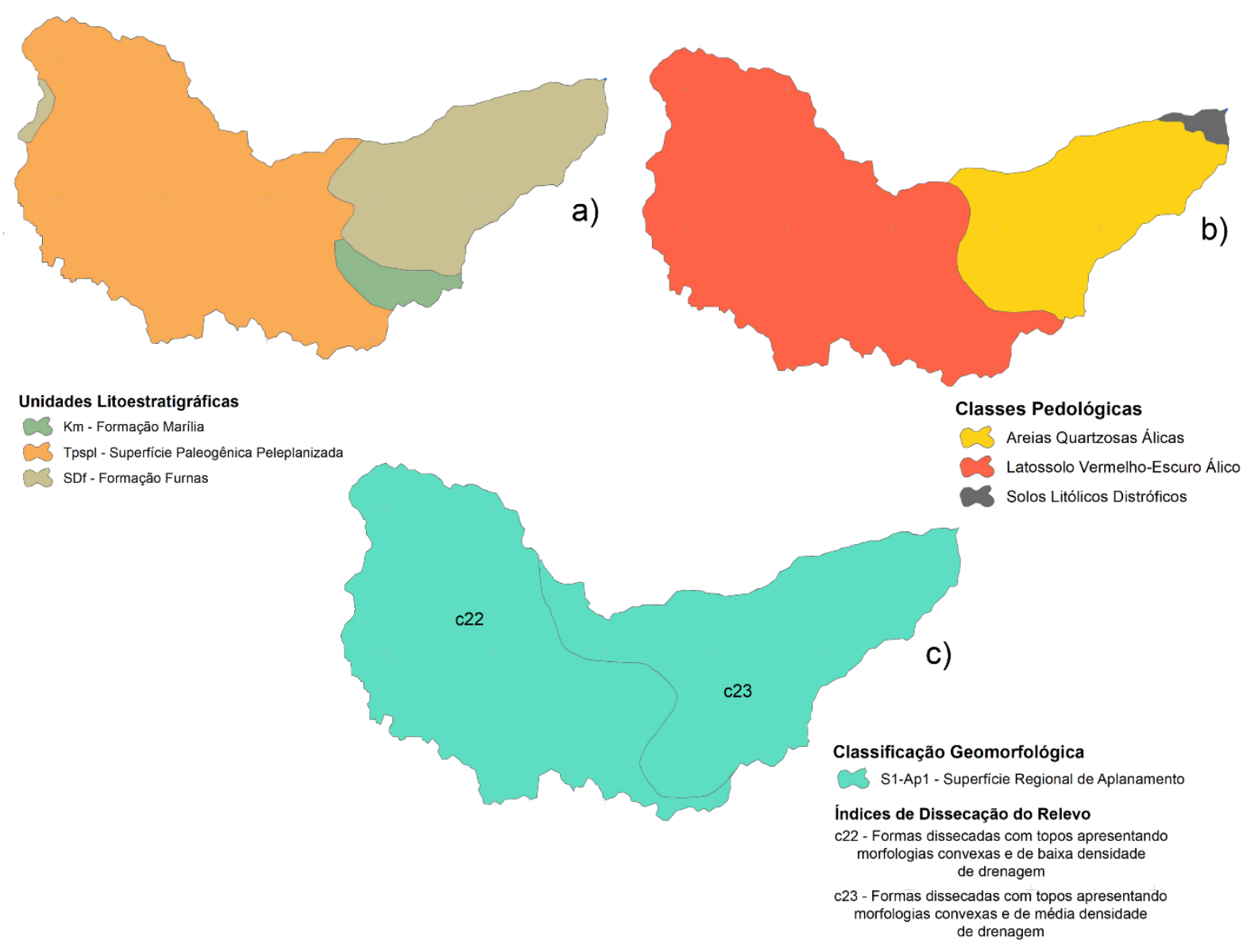

Fonte: Os autores. 
Dentre as unidades de solos destacam-se na bacia os Neossolos Quartzarênico (Areias Quartzosas Álicas) de textura arenosa localizados na região central do território da bacia ocupando $29,22 \%$. Ocorre desde as nascentes até próximo da foz com o rio Ponte de Pedra, onde se desenvolve sobre um relevo suave ondulado composto, predominantemente, por Solo Litólico Distrófico $(1,2 \%)$, unidade que se sustenta sobre a litologia da Formação Furnas caracterizada pela presença de arenitos quartzosos, grosseiro, tendo intercaladas camadas de arenito extremamente micáceo, apresentando frequentemente estratificação cruzada. São solos quimicamente pobres, e com alta taxa de infiltração, devido à sua composição mineralógica conforme verifica-se na geomorfologia estando na unidade c23 que são formas dissecadas e de média densidade de drenagem. Nesse contexto, do ponto de vista pedológico essas áreas são caracterizadas como sendo de alta fragilidade aos processos de desgaste e perda do solo. Estudos realizados por Scopel et al. (2013), observou o desenvolvimento de processos erosivos em solos arenosos numa situação de declividade acima de 3\%, o que mostra a alta susceptibilidade a erosão mesmo em relevo suave ondulado.

Esse grau de vulnerabilidade atribuído pode ser explicado pelo baixo grau de desenvolvimento de processos pedogenéticos identificados pela distribuição dos horizontes/camadas. A hierarquização das classes pedológicas, de acordo com os pesos atribuídos (Tabela 2), apontou vulnerabilidade muito alta em áreas de baixada. Nesse caso, associada à ocorrência de Solos Quartzosos Álicos em planícies fluviais, com drenagem deficiente e baixa velocidade de infiltração da água, favorecendo o escoamento superficial. Os Neossolos Litólicos, que correspondem às áreas de maior declividade, por sua vez, propiciam a remoção de material do solo e inibem processos pedogenéticos.

A região alta da bacia mostrou-se predominantemente formado por Latossolo Vermelho-Escuro, representando 69,57\% da área total da bacia. Esses solos apresentam características litológicas de Formação Paleogênica, composta por siltitos arenosos e arenitos finos a médios e até grosseiros, mineralogicamente nos níveis grosseiros, predominam grãos de quartzo com alguns raros feldspatos caolinizados. Ocupam unidades geomorfológicas de formas suaves onduladas dominadas por colinas convexas. Os latossolos são muito intemperizados, apresentam baixa retenção à umidade, e pequena reserva de nutrientes para as plantas. Por essas características são considerados de baixa suscetibilidade aos processos de movimentos de massa. 
A maior parte da área analisada foi classificada pela baixa a moderada suscetibilidade sendo que essas áreas compreendem a parte alta da bacia e a região da jusante. As características do tipo de solo, usos da terra e declividade foram fatores importantes que levaram essas áreas a obterem baixos valores de fragilidade. Além de que, grande parte das regiões com baixos valores estavam com a cobertura vegetal natural preservada, contribuindo para menores índices de suscetibilidade.

\section{CONSIDERAÇÕES FINAIS}

A caracterização da suscetibilidade do terreno quanto aos movimentos de massa da bacia do córrego Grande mostraram que a região localizada mais na parte central dessa bacia, local onde há maiores graus de declividade do terreno, solo com menores propriedades de firmeza, muito cultivo de pastagem e exposição do solo, obtiveram valores de alta suscetibilidade, caracterizando-os como áreas de risco ao escorregamento do terreno, perda das funções físico-químico do solo e da vegetação. São áreas de risco à proteção da biodiversidade e das comunidades biológicas aquáticas e terrestres. Além de ser um risco aos assentados que na sua grande parte estão localizados nas áreas de maior risco.

Os resultados desse trabalho servem como uma ferramenta na gestão ambiental de áreas de importância ambiental e econômica, servindo como uma proposta de método prévio às instalações de assentamentos rurais, visando conhecer melhor a área na qual procura-se instalar assentamentos, buscando a segurança ambiental dos recursos naturais e da biodiversidade, assim como do homem.

\section{REFERÊNCIAS}

BERTONI, J.; LOMBARDI NETO, F. Conservação do Solo. ed. 6, São Paulo: Ícone, 2008. $355 \mathrm{p}$.

BIGARELLA, J. J.; BECKER, R. D.; SANTOS, G. F. Estrutura e origem das paisagens tropicais e subtropicais. 2.ed. São Paulo: Saraiva. 2007.

BOJÓRQUEZ-TAPIA, L. A.; CRUZ-BELLO, G. M.; LUNA-GONZÁLEZ, L. Connotative land degradation mapping: a knowledge-based approach to land degradation assessment. Environmental Modeling \& Software, v.40, p.51-64, 2013. 
CALIJURI, M. L.; ALVES, J. E. M.; BAPTISTA, A. C.; SANTIAGO, A. F.; LOURES, S. S. P. Proposta metodológica para geração da carta de fragilidade ambiental, utilizando lógica fuzzy e combinação linear ponderada. In: XIII Simpósio Brasileiro de Sensoriamento Remoto, Florianópolis, Brasil, 2007. p. 3311-3318.

COGO, N. P.; LEVIEN, R.; SCHWARZ, R. A. Perdas de solo e água por erosão hídrica influenciada por métodos de preparo, classes de declive e níveis de fertilidade do solo. Revista Brasileira de Ciência do Solo, Viçosa, v.27, n.4, p.743-753, 2003.

CUNHA, E. R.; BACANI, V. M.; AYACH, L. R. Geoprocessamento aplicado à análise da fragilidade ambiental. Revista da ANPEGE, v. 9, n.12, p.89-105, 2013.

EREIO, P. K. B. Qualidade ambiental das nascentes do córrego Grande na bacia do ribeirão Ponte de Pedra (Rondonópolis, Mato Grosso). 2017. 109p. Dissertação (Mestrado em Geografia) - Ciências Humanas e Sociais, Universidade Federal de Mato Grosso, Rondonópolis, 2018.

FORMAN, R. T. T.; ALEXANDER, L. E. Roads and their major ecological effects. Annual Reviews in Ecology e Systematics, v. 29, p. 207-231, 1998.

GARÓFALO, D. T.; FERREIRA, M. C. Mapeamento de fragilidade ambiental por meio de análise geoespacial: uma aplicação na alta bacia dos rios Piracicaba e Sapucaí-Mirim, APA Fernão Dias, MG. Revista do Departamento de Geografia, v.29, p.212-245, 2015.

SANJAY, K. J.; GOEL, M. K. Assessing the vulnerability to soil erosion of the Ukai Dam catchments using remote sensing and GIS. Hydrological Sciences Journal, v.47, n.1, p.3140, 2002.

MIRANDA, R. B.; ESTIGONI, M. V.; MAUAD, F. F. A influência do assoreamento nos reservatórios de centrais hidrelétricas. In: Cristiano Poleto (Org.). Sedimentologia Fluvial: Estudos e Técnicas. Rio de Janiero: Interciência, p.143-178, 2014.

QGIS Development Team 2018. QGIS Geographic Information System. Open Source Geospatial Foundation Project. http://qgis.osgeo.org. 
ROSS, J. L. S. Landforms and environmental planning: Potentialities and Fragilities. Revista do Departamento de Geografia, p. 38-51, 2012.

SANTOS, R. M.; NÓBREGA, M. T.; PAIVA, R. G.; SILVEIRA, H. Análise da fragilidade ambiental no município de Tamboara - PR: aplicação e estudo comparativo de duas metodologias. Geoambiente on-line, n.14, p.93-120, 2010.

SANTOS, F. S. M. Avaliação de processos erosivos a partir da análise integrada do meio físico na bacia hidrográfica do Ribeirão das Pedras, Quirinópolis (GO). 2013.131p. Tese (Doutorado Geociências e Meio Ambiente) - Instituto de Geociências e Ciências Exatas, Universidade Estadual Paulista Júlio de Mesquita Filho, 2013.

SCOPEL, I.; SOUZA, M. S.; MARTINS, A. P. I. Infiltração de água e potencial de uso de solos muito arenosos nos cerrados (savanas) do Brasil. Boletim Goiano de Geografia, v.33, n.2, p.203-219, 2013.

SPORL, C.; ROSS, J. L. S. Análise comparativa da Fragilidade Ambiental com Aplicação de Três Modelos. GEOUSP - Espaço e Tempo, v.15, p. 39-49, 2004.

SEPLAN. Secretaria de Estado de Planejamento. Atlas de Mato Grosso. Cuiabá, 2011.

SETTE, D. M.; TARIFA, J. R. Clima e ambiente urbano tropical: o caso de RondonópolisMT. Revista Intergeo, v.1, p.26-35, 2001.

SENTINEL-2, 2015, 14/03/2018. NASA EOSDIS Land Processes DAAC, USGS Earth Resources Observation and Science (EROS) Center, Sioux Falls, South Dakota (https://lpdaac.usgs.gov), acessado 14/03/2018.

SOUZA, A. P.; MOTA, L. L.; ZAMADEI, T.; MARTIM, C. C.; ALMEIDA, F. T.; PAULINO, J. Classificação climática e balanço hídrico climatológico no Estado de Mato Grosso. Nativa, v.1, n.1, 2013. 
SUAREZ, J. Deslizamientos: análisis geotécnico. 1.ed. Bucaramanga: Universidad Industrial de Santander, v.1, 2009. 590p.

VALLE, I. C.; FRANCELINO, R. M.; PINHEIRO, H. S. K. Mapeamento da fragilidade ambiental na bacia do rio Aldeira Velha, RJ. Floresta e Ambiente, p.295-308, 2016.

VALERIANO, M. de M. 2008. TOPODATA: guia de utilização de dados geomorfométricos locais. São José dos Campos: INPE. Disponível em http://www.dsr.inpe.br/topodata/. Acesso em: 15 março de 2018. 